\title{
Nocardia asteroides Complex
}

National Cancer Institute

\section{Source}

National Cancer Institute. Nocardia asteroides Complex. NCI Thesaurus. Code C86612.

A non taxonomic grouping of bacteria assigned to and including at least four related species from the Nocardia genus. 